\title{
A Look at the Tradition of Lack of Accommodating of Citizens with Disabled Citizens in the People's Republic of China
}

\author{
Zhao Xingran ${ }^{\mathrm{a}}, \mathrm{Mu} \mathrm{Nan}^{\mathrm{a}}, \mathrm{Xu} \mathrm{Xiao}^{\mathrm{a}}$, Liang Yu$^{\mathrm{a}}, \mathrm{Su} \mathrm{Mingxi}^{\mathrm{a}}, \mathrm{Liao}^{\mathrm{a}}{ }^{\mathrm{a}}$, Reine De Ciel $^{\mathrm{a}}$
}

\begin{abstract}
It is common to encounter a citizen with disabled citizens in everyday life. According to data from the second national survey of disabled citizens, the group accounts for $5.26 \%$ of the population of Guangzhou. Citizens with vision, hearing or physical disabled citizens accounts for the largest part of this statistic. Citizens with disabled citizens in China are often treated as inferiors. There is a history of complaints of the lack of physical and service-related accommodation by this group. Citizens with disabled citizens complain that it is very difficult to find a job because of the unfair treatment. Zhang Hai Di is a famous Chinese writer with severe disabled citizens. A true advocate, Di, devoted her life to helping disabled citizens have the same rights as others. This acclaimed writer has played a critical role in advocating the government put forward many policies which have had significant effects on the disabled citizens's daily life. However, there is still room for improvement in China (Wang,2017). For example, the majority of building are lack wheelchair accessibility, and it is a serious problem for the blind and disabled citizens in China. Moreover, most signages and computers are not designed for the blind. Special phones for the deaf citizens are not common.
\end{abstract}

Keywords: Disabled citizens, Public service, Volunteer

\section{Introduction}

This study will review the lack of disabled facilities and current volunteer services for citizens with disabled citizens in China. There is a serious problem for disabled citizens since they are suffering from not having access to services and equipment that they need in order to live a life as normal citizens. The current situation is a serious problem for the community since disabled citizens are a part of group within the Chinese society. According to data from the second national survey of disable people, the group accounts $5.26 \%$ of the population of Guangzhou (GDPF,2018).

For the purpose of the paper, a disabled citizens is defined as a physical or mental impairment that lowers the normal social, economic, and academic functions of an individual to the extent that there is an impediment that lowers the normal activities of daily life in comparison with the general population ( $\mathrm{Wu}, 2016)$. Disabled citizens have proven their value globally in science, business, sports and other fields. For example, Stephen Hawkins has contributed to business and sciences as a physicist, Ernest Miller Hemingway is one of the most famous novelists of the 20th century, and Helen Keller, is the writer of 《Three Days To See $\rangle$. A person who has visual disabled citizens can also write a meaningful book. Even some of disabled citizens take the initiative to participate in Paralympic games. They deserve to be taking care by the society. (Pan, L., \& Ye, J. 2015)

The number of disabled citizens in Guangzhou exceeds 500,000 and a disabled citizens prevention work plan will be launched this year. Guangzhou will be the target city for our following discussion.

\section{Methodology}

A quantitative opinion poll is created and students of the DMU precession EAP preparatory program are invited to take the survey. The survey is conducted by a group of students in higher education who are in language classes at South China University. About 72 responding students express their views on disabled citizens, volunteer service, and public facilities in different ways. These 72 students will study in different fields once transferred to DMU, such as finance, accounting and management. We believe that the group is relevant because of this fact. Additionally, the group of college students is the frontier group of new technology and new ideas in the society. College students are a young and energetic group that can propel social progress. The questionnaire is a survey to find out what is Chinese college students' current attitude towards disabled citizens and make recommendations and guide better value orientation.

The ratio of men to women in the survey is almost equal. From this survey , $45.83 \%$ of students' major is management, $33.33 \%$ of the students major in finance, the rest of the students major in accounting. These students have given us some different views on these issues. Interestingly, most of the students in the survey have encountered disabled citizens in their daily life $(93.06 \%)$ and are willing to help them use public facilities such as wheelchairs and others(94.44\%). A description of that attitudes towards citizens with disabled citizens are more friendly in groups such as students, this undoubtedly brings many conveniences to the life of the disabled citizens. $63.89 \%$ of students think the public is friendly to disabled citizens, but it still have $34.72 \%$ of students think people's attitude to disabled citizens are not friendly. These data can be seen directly that public's attitude toward disabled citizens still needs to be improved. Last but not least, only about half of the students surveyed regularly saw public facilities for disabled citizens such as wheelchairs $(52.78 \%)$, and $44.44 \%$ of those surveyed said the government's safeguards for disabled citizens did not guarantee their life.

\section{Results}

Our group sent out questionnaires to the students who is taking the DMU precession EAP preparatory program and we finally got 72 answers of the questionnaires. The questionnaire gathered data on the student's attitude to the disabled citizens. From this questionnaire, $63.89 \%$ of students 
think that public attitudes to disabled citizens are friendly, but still $34.72 \%$ of students think the public is not friendly enough. It is significant to note that two thirds $(66 \%)$ of the students surveyed have not participated in volunteer activities but are willing to participate in volunteer activities organized by the volunteer program which belongs to the government in the future. Therefore, lots of people have not participated in the volunteer service but they do want to do that if there are some opportunities. The policy makers should put forward more programs to involve as many people as possible to participate in the volunteer activities. The public are aware of the importance of volunteer service, and they just need the opportunity to actually participate.

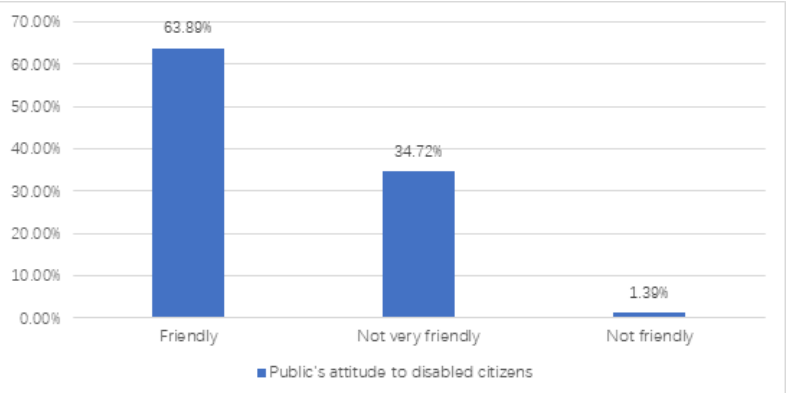

Figure 1. Public's attitude to disabled citizens

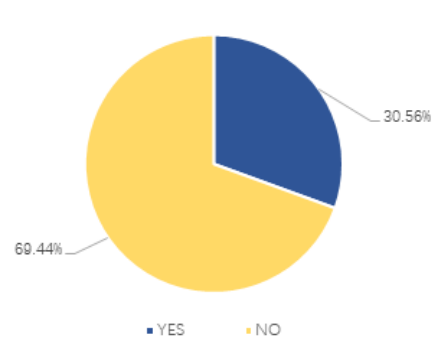

Figure 2. Have students ever been to a disabled volunteer program

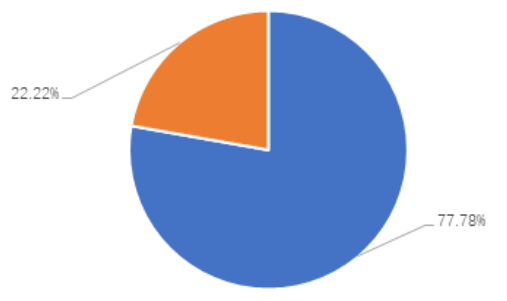

-Willing to " No willing to

Figure 3. Student's opinion of participate volunteer activities

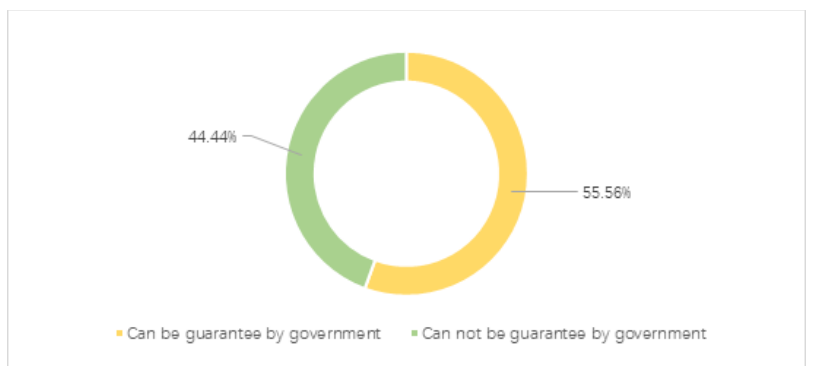

Figure 4. Government's safeguards of disabled citizens Discussion

According to the second national sample survey of disabled citizens, the ratio of disabled citizens in Guangzhou is $5.26 \%$, and the total population of disabled citizens is 52,120. Among this large population, visual disabled citizens take up $11.69 \%$, hearing disabled citizens take up $21.65 \%$, language disabled citizens take up $2.02 \%$, physical disabled citizens take up $23.23 \%$, intellectual disabled citizens take up $4.91 \%$, mental disabled citizens take up $13.65 \%$, and $22.94 \%$ for multiple disabled citizens. The specific data is: 60,927 visual disabled citizens, 112,839 hearing disabled citizens, 10,529 language disabled citizens, 121,074 physical disabled citizens, 25,592 intellectual disabled citizens, 70,675 mental disabled citizens, and 119,564 multiple disabled citizens (Guangzhou disabled person 's federation,2018).

From 2014 to 2017, the standard of living allowance and subsidy for the disabled citizens in Guangdong province have improved gradually. The living allowance standard for the disabled citizens has been raised from 100 yuan per year to 600 yuan per year in 2014. In 2017, the allowance for disabled citizens has been reached to 2400 per year. Since the disabled citizens subsidy and corresponding assistance system has been implemented in various places, if it is higher than this standard, it shall continue to be implemented in accordance with the original regulations (Guangdong disabled citizens subsidy standard,2018).

The decreasing of the personal income tax and exempting of the sales tax show that government is working on releasing tax burden on the disabled citizens. Government subsidies can also improve the living standards of disabled citizens. As far as our study is concerned, government has paid more attention to disabled citizens. Between 2014 to 2017 , there is a dramatically increasing on the benefits which are given to the disabled citizens. The expenditures of families with disabled citizens have been reduced due to these benefits.

Our first question is about whether the government should provide more volunteer programs to help disabled citizens or not. The collecting data shows people are willing to do volunteer, but the government and private sector do not have enough platforms to provide such opportunities. Government needs to use more resources to support volunteer program. For example, government can make more volunteer programs like supporting community volunteers interview homes of disabled citizens in order to help them understand their physical conditions and living conditions, encourage them to have confidence and face lives with positive attitudes. Through practical actions, it can strengthen the connection between community volunteers and disabled citizens and express respect, care and assistance to disabled citizens. In 
addition, community volunteers have more comprehensive grasp of the current situation and needs of the disabled citizens in the community. They can provide service based on their needs.

The second question is about whether the government should build more wheelchair accessible buildings for disabled citizens in China. No matter in large cities or small towns, we rarely see disabled citizens. It is found that disabled citizens prefer staying at home instead of going outside. Actually, the difficulties for blocking them from crossing their homes are embarrassed and inconvenient. Most disabled citizens think that going out is really "too much trouble", and travel is extremely inconvenient. They choose to stay at home for a long time, and autism becomes their inevitable choice. (FAN.X,2017)

China has many accessible facilities, however, many facilities are outdated and need to be renew. Most of the accessible facilities are not being well used. For example, there are always some obstacles on the blind road, buses are not equipped with wheelchair lifts, lots of buildings like bank are not built with a ramp. The research does support our contention that government should solve these problems.

\section{Conclusion}

There are close to 100 million disabled citizens in China, it accounts for 7 percent of the Chinese population. Every country has vulnerable population, a significant proportion of the disabled citizens are born disabled, their physical or psychological defects are not their fault. Their state of existence is the most practical reflection of one country's level of civilization. The survey inquies students' attitude to the disabled citizens and uses the questionnaire survey to obtain information about young people's attitude to disabled citizens. Contrary to the original hypothesis, we find that many people are willing to be the volunteers for the disabled citizens, but there are limited opportunities. Although government has provided increasing subsidies for the disabled citizens, family members of disabled citizens still need to go outside to do some jobs in order to earn some money to support the family. The family members may not have enough time to accompany with disabled citizens. Government subsidies are far away from feeding the whole family. We found that there are strong needs for reasonable accommodations, although we also found the existence of unused resources. We strongly suggest further research about this matter to discover solutions for the improvement of existing facilities and accommodation utilization rates.

\section{Reference}

Bai Jia Hao (2018), the New Policies for Disabled citizensGuangdong disabled subsidy standard, https://rl.mbd.baidu.com/6s6sst5?f=cp

FAN.X.(2017), Why do you rarely see disabled citizens on the street. Jue Ce, 13rd Oct. Available from: http://www.sohu.com/a/197942398_158217

Guangzhou disabled person's federation (GDPF) (2018), The Number of Disabled citizens, http://www.gz.gov.cn/GZ53/index1.shtml

Pan, L., \& Ye, J. (2015). Family Care of People with Intellectual Disabled citizens in Rural China: A Magnified Responsibility. Journal of Applied Research in Intellectual Disabled citizens, 28(4), 352-366.

WANG, X, H (2017) The disabled worker should be the noble person who improve the way of life for the disabled. Chinatimes.30th Dec. Available from: http://www.chinatimes.net.cn/article/73610.html.

$\mathrm{Wu}$ J. (2016). Bureaucratic Benevolence: Disabled citizens Inclusion and Special Education in China. In The Global Convergence Of Vocational and Special Education (pp. 85-111). Routledge. 